\title{
Perceptions toward the Nursing Profession to Predict Attrition Factors among Female Saudi Nursing Students: Implications to Enrolment and Drop-Out
}

\author{
Dr. Sitah Alshutwi ${ }^{* 1}$, Malak Alharbi ${ }^{2}$, Dalal Almutairi ${ }^{2}$, Reem Alotaibi $^{2}$ \\ ${ }^{1}$ Assistant Professor, College of Nursing, King Saud Bin Abdulaziz University for Health Sciences; \\ King Abdullah International Medical Research Center \\ ${ }^{2}$ Resident SN1, National Guard Health Affairs \\ *Corresponding author: Dr. Sitah Alshutwi; shutwis@ksau-hs.edu.sa
}

Received 28 August 2021;

Accepted 14 September 2021;

Published 16 September 2021

\begin{abstract}
Background: The attrition rate among nursing students is a serious phenomenon; however, this issue has attracted such little attention particularly in Saudi Arabia. Objective: This study aimed to assess students' perceptions toward nursing and the factors and intention that influenced them to drop out from the program. The study also examined the predictors of students' perceived factors and intention to quit nursing. Design: Quantitative, correlational, and cross-sectional design. Method: A convenience sample of 162 baccalaureate nursing students was surveyed. A logistic regression analysis was implemented to examine the predictor variables on students' perceived factors and intention to quit nursing. Results: The overall agreement of the perceptions of nursing students toward the nursing profession can be interpreted as positive. In addition, the perceived factors are strong, whereas their intention to quit nursing is low. Nursing students' age, marital status, and having no children had significant correlations with the factors that cause drop-out from the nursing program. Having a friend or relative who is a nurse and the positive family's reaction to enrolment to nursing had significant relationships with the low level of intention to quit nursing. The strong and positive agreement with their perceptions of nursing as a profession had predictive effects on the perceived factors that cause dropping out from the nursing program. Conclusions: Female Saudi nursing students had positive perceptions and low intention to quit nursing but strongly agreed with the factors that cause drop-outs. As previous studies showed conflicting views with the current study, a further investigation involving students (males and females) and the public on a national level is paramount to gain a clear view of nursing in the country. Students and public view of nursing can affect and influence high school students who plan to enroll into the nursing program.
\end{abstract}

Keywords: Drop-out factors; Intention to quit; Nursing student; Perception; Saudi Arabia

\section{Introduction}

The coronavirus disease 2019 (COVID-19) pandemic continues to be a health concern with global cases surpassed 202.2 million and the number of deaths reached over 4.2 million. As of August 8, 2021, the confirmed cases in Saudi Arabia reach over 531,000 with the number of deaths of more than 8,300 (Johns Hopkins University and Medicine, 2021). This pandemic has impacted all aspects of life and caused fears and anxiety to people. Particularly, the pandemic challenges nurses and nursing students who are also exposed to potential risks of getting infected with the virus during their clinical education (Albaqawi et al., 2020; Alkhamees et al., 2020).

Nursing students should have a positive perception of the profession they pursue (Al Nozha \& Fadel, 2017; Huang \& Xiao,
2003) particularly with the ongoing pandemic. The development of a strong nursing pre-professional identity is also important for nursing students to view nurses as knowledgeable and competent healthcare professionals (Browne et al., 2018). The perception toward the nursing profession is an impelling factor in the intention of nursing students to quit or complete the nursing program (Mansour et al., 2016). However, the attrition rate of students in nursing programs remains a major challenge for nursing educators and deans of nursing programs (Jeffreys, 2015; Jinks et al., 2014; Merkley, 2016).

With the current shortage of Saudi nurses and the increased demand for healthcare, the need for more competent nursing graduates must be escalated to meet the needs of the Saudi population. However, this case is jeopardized by the attrition rate among Saudi nursing students. Moreover, the attrition of student 
nurses and drop-out rates are serious issue in undergraduate nursing education programs globally (Merkley, 2016). The average attrition rates reach $50 \%$ for students in baccalaureate nursing programs (Newton \& Moore, 2009). In 2011, a total of 75,000 qualified nursing students dropped out from nursing programs (American Association of Colleges of Nursing, 2012, 2019). Mostly, students' attrition from nursing programs occurs during the first year, which is called the pre-clinical or pre-professional year (Andrew et al., 2008).

The literature discussed some factors that might cause student attrition, such as increased study workload, lower grade point average (GPA), and clinical environment difficulties (Mansour et al., 2016). The perception of nursing students toward the nursing profession is an influencing factor in students' intention to leave nursing (Mansour et al., 2016). In the United Kingdom (UK), the clinical placement experience of nursing students is an influential aspect, particularly relating to their own self-appraisal and relationships with other healthcare providers (Clements et al., 2016). Brodie et al. (2004) aimed to gain an indepth understanding of changing perceptions of nursing and their impact on students enrolled in nursing education. They found that the perception of students about nursing as a profession is unfortunate. Most of the students felt that nurses are underpaid and overworked with little respect received (Brodie et al., 2004). In South Korea, nursing students with intentions to quit the nursing program were less likely to practice career preparation behaviors and had lesser levels of vocational consciousness and social responsibility (Kim et al., 2021). These factors are consistent with a half a century of descriptive literature review, which collated the research evidence from 1965 to 2015 . The review showed that the factors that cause attrition in nursing include the nursing student, clinical training, learning environment and nursing educator, and policies (Merkley, 2016).

Although the attrition rate among nursing students is a serious phenomenon, this issue has attracted such little attention, particularly in Saudi Arabia. Therefore, this study aims to determine the attrition attention among nursing students in their pre-professional or first year in the nursing program. Furthermore, this study aimed to determine students' perception toward nursing as a profession and whether their perceptions and perceived attrition factors influence their intention to drop-out from the nursing program.

\section{Materials and Methods}

\section{Research design}

A quantitative, descriptive, correlational, and cross-sectional design guided this study. This study adhered to Strengthening the reporting of observational studies in epidemiology (STROBE) guidelines for cross-sectional studies.

\section{Setting and sample}

The study was conducted in a university for health sciences located in Riyadh City, Saudi Arabia, which is governed by the Ministry of Education of the country. This university is nationally recognized and has a well-established reputation for quality and excellence in education for health sciences. Moreover, the school has a four-year university-based Bachelor of Science in Nursing (BSN) program and an additional year of the internship training program in its affiliated hospital. The first year of the BSN program is considered a preparatory year, wherein basic courses are introduced, and the nursing proper begins in the second year of the program. Specifically, this study was conducted at the College of Nursing of the university. The following were the criteria for inclusion in this study: (1) Saudi nationals, (2) enrolled full time in the university during the data collection period, and (3) consented to participate in the study. Nursing students from levels 5 to 8 were excluded from participating in the study. The sample size for the study was calculated using the Raosoft software. The total population at the time of data collection was 354 at the site of this study. The calculation revealed a sample size of 185 at a $5 \%$ margin of error and $95 \%$ confidence level. We distributed 200 surveys to meet the required number of samples.

\section{Instrumentation}

Data were gathered using an online survey with four parts, with three scales having a total of 38 items along with six demographic questions of female Saudi nursing interns. For the first part, that is, demographic variables, no identifying information was gathered to maintain participant privacy. Demographic variables included the students' age, university level, marital status, having children, having a nurse friend or relative, and the family's reaction to enrolment to nursing.

The second and third parts contained 22 questions in assessing the perceptions of nursing students of nursing as a profession and 13 questions in assessing the factors that cause drop-outs from the nursing program. Both scales were constructed by the research team based on previous studies (Al Jarrah, 2013; Saied et al., 2016). The content validity of the two scales was reviewed and evaluated by three content experts with a $\mathrm{PhD}$ degree in nursing. The final tool was pilot-tested with 20 students. Considering that this study included first-year students, the survey was translated into Arabic language while maintaining the English version. For the perception scale, the responses to all items were set in a five-point Likert scale $(1=$ strongly disagree, $2=$ somewhat disagree, $3=$ neither, $4=$ somewhat agree, $5=$ strongly agree), with high scores indicating a positive perception. Meanwhile, the responses to all items in the factor scale were set in a five-point Likert scale ( 1 = strongly disagree, 2 = somewhat disagree, 3 = neither, 4 = somewhat agree, $5=$ strongly agree). High scores indicated agreement that the factors highly cause dropouts.

The fourth part of the questionnaire was used to assess the students' intention to leave the profession, which was measured using the Turnover Intention Scale developed by Cammann et al. (1979). The responses to the three items were set in a 5-point Likert scale $(1=$ strongly disagree, $2=$ somewhat disagree, $3=$ neither, $4=$ somewhat agree, $5=$ strongly agree), with high scores indicating agreement with the intention to withdraw or quit the nursing. The scale had three inventory items, with one reversed item. The scale had an established validity and a reliability of 0.80 (Cammann et al., 1979).

\section{Ethical considerations}

Permission from the copyright holder of the tool was obtained before data gathering. Also, before starting data collection, the study was approved by the Research Unit of the College of Nursing in the university for health sciences under ethical approval number: IRBC/0435/19. An informed consent form was asked from each participant before answering the survey. Adequate information was provided to the respondents during the recruitment phase, and the respondents were told about their rights. Participation in the study was voluntary, and those who opted not to participate were respected. No incentives were given for participation. The research team maintained confidentiality and privacy about the information obtained from participants. The data 
were kept confidential, and only the research team had access to the surveys.

\section{Data collection}

Once the administrative and ethical approvals of the study were obtained, the researchers distributed the survey to the potential participants. The consent contained significant information about the study. Consent was implied once the participants continue with the survey. After the students completed the survey, their responses were collected by the researchers and entered into a database.

\section{Data analysis}

All data were entered and analyzed using SPSS for IBM version 22. Descriptive statistics analysis was used to describe the sample characteristics by using the mean, standard deviation, frequencies, and percentages. The chi-square $\left(X^{2}\right)$ and Pearson's correlation coefficient ( $r$ ) were used to measure the strength of the correlation and prediction of dependent variables. A logistic regression analysis was performed to examine the predictors of the nursing students' factors and intention to withdraw or quit the nursing program. The p-value was used to evaluate the significance of the correlation and prediction.

\section{Results}

Among the 162 female nursing students (response rate: $81.0 \%$; Table 1$)$, the majority were aged $18-20$ years old $(88.0 \%)$, at their first year (levels 1 and 2; 72.0\%), and single (99.0\%). Moreover, they have no children $(99.0 \%)$, had a nurse friend or relative $(56.0 \%)$, and have a positive family's reaction to enrolment to nursing $(54.0 \%)$.

\section{Nursing students' perceptions toward the nursing profession}

The overall mean score of the level of agreement of the perceptions of nursing students toward the nursing profession was high or strong $($ Mean $=3.59$ from 5; $\mathrm{SD}=1.01$; Table 2). The nursing students reported the highest level of perceptions in "Nursing is a human profession" (Mean $=4.79 ; \mathrm{SD}=0.55$ ), followed by "Nursing profession is an essential profession in any society" (Mean $=4.78 ; \mathrm{SD}=0.58)$, "Nursing profession is a respectful profession" (Mean $=4.69 ; \mathrm{SD}=0.63$ ), "Nursing profession is significant in patient's recovery" (Mean $=4.62 ; \mathrm{SD}=0.70)$, and "Nursing is a caring profession in which ethical standard of care is maintained" (Mean $=4.56 ; \mathrm{SD}=0.73$ ). Other items perceived very highly by nursing students include the following: "Nursing profession helps in promotion of health and prevention of disease" (Mean $=4.48 ; \mathrm{SD}=0.82)$, "Nursing is a prestigious profession" (Mean $=4.36 ; \mathrm{SD}=0.95$ ), "Nursing profession is an opportunity for personal growth" (Mean $=4.30 ; \mathrm{SD}=0.88)$, and "Nursing profession provides self-actualization" (Mean $=4.26 ; \mathrm{SD}=0.83$ ). Two perception items had low levels including the following: "Nursing is a profession where anyone could be a nurse easily" (Mean $=2.28 ; \mathrm{SD}=1.18$ ), and "Nursing is a women's profession" (Mean $=1.99 ; \mathrm{SD}=1.14)$. The lowest levels of perception toward the nursing profession were reported in the following items: "Nursing profession is similar to that of the servant's job" (Mean = 1.56; $\mathrm{SD}=1.02$ ) and "Nursing profession is where nurses waste a lot of time being busy doing nothing" (Mean $=1.46$; $\mathrm{SD}=0.82$ ).
Nursing students' perceived factors that cause drop-outs in the nursing program

The overall mean score of the students in the factors that cause drop-outs in the nursing program was high (Mean $=3.48$ from 5; $\mathrm{SD}=0.22$; Table 3 ). The highest mean score was reported in the perceived factor "increased study workload" $($ Mean $=4.14 ; \mathrm{SD}=$ $0.97)$, followed by "illness or poor health" (Mean $=3.78$; SD $=$ 1.15 ), "student dissatisfaction" (Mean $=3.70 ; \mathrm{SD}=1.17$ ), "low first-year GPA" (Mean = 3.69; SD = 1.28), "difficulty in English language" $($ Mean $=3.69 ; \mathrm{SD}=1.24)$, "clinical environment difficulties" (Mean $=3.65$; SD $=0.92$ ), and "low second-year GPA" $($ Mean $=3.54 ;$ SD $=1.24)$. The following factors had moderate levels in causing drop-out including "teaching contents are far from what are expected" (Mean $=3.25 ; \mathrm{SD}=1.13$ ), "family pressure to change major (career)" (Mean $=3.24$; $\mathrm{SD}=1.49$ ), "lack of family support" (Mean = 3.19; SD = 1.44), "bad impression from the family and relatives about nursing" (Mean $=3.17$; SD $=$ 1.45 ), "culture view about nursing" (Mean $=3.11$; $\mathrm{SD}=1.42$ ), and "vast difference between lectures at school and actual practice" (Mean = 3.06; SD = 1.13).

\section{Nursing students' intention to withdraw or quit the nursing program}

The overall mean score of nursing students' intention to withdraw or quit nursing was low (Mean $=2.00$ from $5 ; \mathrm{SD}=1.23$; Table 4). Nursing students reported low levels of intention to withdraw or quit the nursing program in the following three items: "It is very likely that I will actively look for new specialty next year" (Mean = 2.07; $\mathrm{SD}=1.31$ ), "I often think about quitting" (Mean $=2.06$; SD $=1.29$ ), and "If I could choose again, I would choose to study nursing" (Mean $=1.87$; $\mathrm{SD}=1.09)$.

Relationship among socio-demographic profiles, perceptions of nursing as a profession, factors that cause drop-outs, and intention to withdraw or quit nursing

In Table 5, the findings showed a significant positive relationship between age and the factors that cause nursing student drop-outs $\left(X^{2}=8.26 ; p=0.04\right)$ and intention to withdraw or quit nursing $\left(X^{2}\right.$ $=13.78 ; p=0.01)$. Marital status $\left(X^{2}=8.19 ; p=0.04\right)$ and having no children $\left(X^{2}=16.49 ; p=0.001\right)$ had significant positive relationships on the factors that cause student drop-outs. Meanwhile, having a nurse friend or relative $\left(X^{2}=8.26 ; p=0.04\right)$ and family's reaction to enrolment to nursing $\left(X^{2}=8.26 ; p=0.04\right)$ had positive significant relationships on students' intention to withdraw or quit nursing.

\section{Predictors of the students' intention to quit or withdraw from} the nursing program

Table 6 shows the results of the regression analysis. Students' perceptions of nursing as a profession had significant effects on the perceived factors that cause drop-outs $(\beta=0.830, p=0.03,95 \% \mathrm{CI}$ $=0.09,1.47)$ but no significant effects on their intention to quit or withdraw from the nursing program $(\beta=0.240, p=0.50,95 \% \mathrm{CI}=$ $0.03,0.51)$. Moreover, students' perceived factors that cause dropouts had no significant effects on their intention to quit or withdraw from the nursing program $(\beta=0.052, p=0.51,95 \% \mathrm{CI}=$ $0.02,0.49)$.

Table 1: Socio-demographic profile of the participants $(N=162)$

\begin{tabular}{|l|l|l|}
\hline Socio-demographic profile & f & \% \\
\hline Age (Years) & & \\
\hline $18-20$ & 143 & 88.0 \\
\hline
\end{tabular}




\begin{tabular}{|l|l|l|}
\hline Above 20 & 19 & 12.0 \\
\hline University level & & \\
\hline Level 1 (Year I, Semester 1) & 81 & 50.0 \\
\hline Level 2 (Year I, Semester 2) & 35 & 22.0 \\
\hline Level 3 (Year II, Semester 1) & 4 & 2.0 \\
\hline Level 4 (Year II, Semester 2) & 42 & 26.0 \\
\hline Marital Status & & \\
\hline Single & 160 & 99.0 \\
\hline Married & 2 & 1.0 \\
\hline Having children & & \\
\hline With children & & 1.0 \\
\hline Without children & 2 & 99.0 \\
\hline Having a friend or relative who is a nurse & 160 \\
\hline Yes & & \\
\hline No & & 56.0 \\
\hline Family's reaction to enrolment to nursing & 90 \\
\hline Positive & 72 & 44.0 \\
\hline Negative & & \\
\hline Natural & 88 & \\
\hline Total & 24 & 54.0 \\
\hline & 50 & 15.0 \\
\hline & $\mathbf{1 6 2}$ & 31.0 \\
\hline & $\mathbf{1 0 0 . 0}$ \\
\hline
\end{tabular}

Table 2: Perceptions of the participants of nursing as a profession $(N=162)$

\begin{tabular}{|c|c|c|}
\hline Items & Mean & SD \\
\hline \multicolumn{3}{|l|}{ Nursing profession is: } \\
\hline 1. A respectful profession. & 4.69 & 0.63 \\
\hline 2. An occupation and not a profession. & 3.02 & 1.38 \\
\hline 3. A women's profession. & 1.99 & 1.14 \\
\hline 4. similar to that of the servant's job. & 1.56 & 1.02 \\
\hline 5. A well appreciated profession in the society. & 3.85 & 1.19 \\
\hline 6. A prestigious profession. & 4.36 & 0.95 \\
\hline 7. A dangerous profession. & 3.45 & 1.39 \\
\hline 8. An extremely hard profession that does not receive enough appreciation. & 3.80 & 1.29 \\
\hline 9. An essential profession in any society. & 4.78 & 0.58 \\
\hline 10. A human profession. & 4.79 & 0.55 \\
\hline 11. An independent profession by which nurses make decisions for themselves. & 3.04 & 1.20 \\
\hline 12. A significant in patient's recovery. & 4.62 & 0.70 \\
\hline 13. Helps in promotion of health and prevention of diseases. & 4.48 & 0.82 \\
\hline 14. Provides self-actualization. & 4.26 & 0.83 \\
\hline 15. Where nurses are given a chance to use their own initiative in their work. & 3.93 & 1.01 \\
\hline 16. Where nurses obey doctor's order without questioning them. & 3.17 & 1.22 \\
\hline 17. Where nurses waste a lot of time being busy doing nothing. & 1.46 & 0.82 \\
\hline 18. A profession which I would like my child to pursue to become a nurse. & 3.80 & 1.21 \\
\hline 19. A profession where anyone could be a nurse easily. & 2.28 & 1.18 \\
\hline 20. An opportunity for personal growth. & 4.30 & 0.88 \\
\hline 21. A caring profession in which ethical standard of care is maintained. & 4.56 & 0.73 \\
\hline 22. Actually equal to other professions. & 2.70 & 1.42 \\
\hline Over-all Mean & 3.59 & 1.01 \\
\hline
\end{tabular}

Table 3: Factors that cause drop-out of the participants in the nursing program $(N=162)$

\begin{tabular}{|l|l|l|}
\hline Factors & Mean & SD \\
\hline 1. Increased study workload & 4.14 & 0.97 \\
\hline 2. Clinical environment difficulties & 3.65 & 0.92 \\
\hline 3. Student dissatisfaction & 3.70 & 1.117 \\
\hline 4. Illness or poor health & 3.78 & 1.15 \\
\hline 5. Vast differences between lectures at school and actual practice & 3.06 & 1.13 \\
\hline 6. Teaching contents are far from what are expected & 3.25 & 1.13 \\
\hline 7. Low first-year grade point average (GPA) & 3.69 & 1.28 \\
\hline 8. Low second-year GPA & 3.54 & 1.24 \\
\hline 9. Family pressure to change major (Career) & 3.24 & 1.49 \\
\hline 10. Bad impression from the family and relatives about nursing & 3.17 & 1.45 \\
\hline 11. Lack of family support & 3.19 & 1.44 \\
\hline
\end{tabular}




\begin{tabular}{|l|l|l|}
\hline 12. Culture view about nursing & 3.11 & 1.42 \\
\hline 13. Difficulty in English language & 3.69 & 1.24 \\
\hline Over-all Mean & $\mathbf{3 . 4 8}$ & $\mathbf{1 . 2 2}$ \\
\hline
\end{tabular}

Table 4: Intention of the participants to withdraw or quit nursing $(\mathrm{N}=162)$

\begin{tabular}{|l|l|l|}
\hline Items & Mean & SD \\
\hline 1. I often think about quitting. & 2.06 & 1.29 \\
\hline 2. It is very likely that I will actively look for new specialty next year. & 2.07 & 1.31 \\
\hline 3. If I could choose again, I would choose to study nursing. ${ }^{r}$ & 1.87 & 1.09 \\
\hline Over-all Mean & $\mathbf{2 . 0 0}$ & $\mathbf{1 . 2 3}$ \\
\hline
\end{tabular}

Note: ${ }^{r}$ Reverse scored item.

Table 5: Tests of relationships $(\mathrm{N}=162)$

\begin{tabular}{|l|l|l|l|l|l|l|l|}
\hline Socio-demographic profile & \multicolumn{2}{l|l}{$\begin{array}{l}\text { Perceptions of nursing as } \\
\text { a profession }\end{array}$} & \multicolumn{2}{l|}{$\begin{array}{l}\text { Factors that cause } \\
\text { drop-out }\end{array}$} & $\begin{array}{l}\text { Intention to withdraw or } \\
\text { quit nursing }\end{array}$ \\
\hline & $X^{2}$ & $p$-value & $X^{2}$ & $p$-value & $X^{2}$ & $p$-value \\
\hline Age & 2.80 & 0.25 & 8.26 & $0.04^{*}$ & 13.78 & $0.01^{* *}$ \\
\hline Year level & 2.59 & 0.86 & 7.95 & 0.54 & 18.70 & 0.10 \\
\hline Marital status & 1.19 & 0.55 & 8.19 & $0.04^{*}$ & 2.73 & 0.60 \\
\hline Having children & 1.80 & 0.41 & 16.49 & $0.001^{* * *}$ & 4.12 & 0.39 \\
\hline Having a friend or relative who is a nurse & 0.24 & 0.89 & 2.99 & 0.39 & 19.62 & $0.001^{* * *}$ \\
\hline Family's reaction to enrolment to nursing & 3.06 & 0.55 & 4.34 & 0.63 & 45.21 & $<0.001^{* * *}$ \\
\hline
\end{tabular}

* Significance level at $\mathrm{p} \leq 0.05$

$* *$ Significance level at $\mathrm{p} \leq 0.01$

$* * *$ Significance level at $\mathrm{p} \leq 0.001$

Table 6: Regression analysis $(\mathrm{N}=162)$

\begin{tabular}{|l|l|l|l|l|l|l|l|}
\hline Study variables & $\boldsymbol{r}$-value & $\boldsymbol{\beta}$ & $\boldsymbol{S E}$ - $\boldsymbol{b}$ & Beta & $\boldsymbol{t}$ & $\boldsymbol{p}$-value & $\mathbf{9 5 \%}$ CI \\
\hline $\begin{array}{l}\text { Perceptions of nursing as a profession versus } \\
\text { factors that cause drop-out }\end{array}$ & 0.171 & 0.830 & 0.038 & 0.170 & 2.19 & $0.03^{*}$ & $0.09-1.47$ \\
\hline $\begin{array}{l}\text { Perceptions of nursing as a profession versus } \\
\text { intention to withdraw or quit nursing }\end{array}$ & 0.053 & 0.240 & 0.036 & 0.053 & 0.67 & 0.50 & $0.03-0.51$ \\
\hline $\begin{array}{l}\text { Factors that cause drop-out versus intention to } \\
\text { withdraw or quit nursing }\end{array}$ & 0.053 & 0.052 & 0.050 & 0.054 & 0.69 & 0.51 & $0.02-0.49$ \\
\hline
\end{tabular}

Note: $\beta$ is the unstandardized coefficients, $S E-b$ is the standardized error, and CI is the confidence interval. $R^{2}=0.29 ;$ adjusted $R^{2}=0.23$

*Significance level at $p \leq 0.05$

\section{Discussion}

This study assessed the perceptions of nursing as a profession, the factors that cause drop-outs, and the intention of female Saudi nursing students toward quitting the nursing program. Critical findings on students' perceptions toward the nursing profession and factors that cause attrition were obtained. These findings can contribute to the development and implementation of policy and educational interventions. That is, the factors that cause attrition in nursing can be minimized or eliminated to prevent loss among the future members of the nursing workforce.

Nursing students reported that $56.0 \%$ of them had a friend or relative who is a nurse, and $54.0 \%$ of them had positive family reactions when they enrolled in the nursing program. The findings suggested that the view of nursing as a profession among the new generation of Saudi youth has improved, which is similar to that of several studies depicting that Saudi society's view of nursing has shown dramatic positive change compared with previous generations (Alharbi et al., 2019; Almutair \& Redwan, 2016; Saied et al., 2016). These results are connected showing that age $(p=0.01)$, having a nurse friend or relative $(p=0.001)$, and the positive family's reaction to enrolment to nursing $(p<0.001)$ had significant relationships with the low level of intention to withdraw or quit nursing. This result implied that when younger nursing students at their first-year level know someone who is a nurse (a friend or relative) and have their families' support in studying nursing, attrition is low, and they would likely graduate from the nursing program. However, these findings are inconsistent with those of another Saudi study, indicating that the nursing profession in Saudi Arabia still has a negative public image (Elmorshedy et al., 2020). Hence, the conflicting results require further investigation involving Saudi nursing students (males and females) and the public across the country to gain a clear national perspective and understanding of the actual image of nursing. Additionally, nursing students' age $(p=0.04)$, marital status ( $p=$ $0.04)$, and having no children $(p=0.001)$ had significant correlations with the factors that cause drop-outs from the nursing program. The findings implied that the female Saudi nursing students who were in younger confined age range, mostly single, and without major family commitments and responsibilities because they did not have children to take care of had expressed a strong agreement of experiencing the factors that cause drop-outs from the nursing program. These findings are consistent where similar characteristics were reported in previous Saudi studies (Al Nozha \& Fadel, 2017). Additionally, a Saudi study demonstrated a significant negative relationship between nursing student's age and perceived stress where stress results in depression, poor health, and low GPA (Al-Gamal et al., 2018).

The overall level of agreement of the perceptions of nursing students toward nursing as a profession can be interpreted as positive, as manifested by the strong level of agreement with an 
overall mean score of 3.59 from 5. Meanwhile, the nursing students exhibited a very strong level of agreement in the nine perception items of the scale. They perceived the very highly nursing profession as a human profession, that is essential in any society, a respected profession that is significant in patients' recovery, and a caring profession in which ethical standard of care is maintained. In addition, the nursing students perceived very highly nursing as a prestigious profession that helps in promoting health and prevention of disease, allows personal growth, and provides self-actualization for nurses. The findings imply that the nursing students had very high regard and belief in the program they are pursuing. Thus, while studying nursing, they already had a strong sense of pre-professional identity of what they will become after completing the nursing program. Browne et al. (2018) stated that having a strong pre-professional identity is essential for nursing students to view nurses as healthcare professionals who are competent and knowledgeable, helping them in transitioning as they move through the nursing degree. The findings could also indicate that the nursing students had a collective identity or representation of the nursing profession as they perceived it very high or more positively. This result is similar to a Canadian study, indicating that nursing students held a positive image of the nursing profession (Grainger \& Bolan, 2006). However, the findings are surprising because of the poor identity and public image of nursing in Saudi Arabia (Elmorshedy et al., 2020).

Currently, the nursing profession in the country faces substantial challenges brought by the low level of community awareness and poor public image of the nursing profession. Thus, recruiting high school students and retaining them into nursing education is difficult, including improving their sense of nursing identity (Elmorshedy et al., 2020). Meanwhile, an Australian study revealed that students in their first year in the nursing program showed a robust professional identity in the role of the nurses as a professional caregiver, having qualities including the following: caring, empathy, respect, and tolerance (Browne et al., 2018). On the contrary, the results of a study in Norway reported that the perception of nursing students about the content of the subject of nursing was unclear and differs from the expectations expressed in the curriculum (Granum, 2004). In the Republic of Korea, a study found a negative result, where nursing students experienced incivility during their clinical training and they felt disrespected and neglected by their preceptors (Ahn \& Choi, 2019). The results of the current study are also contrary to those of a recent study in the country where only $32.5 \%$ of the 502 Saudi adults who participated in the study desired to get nursing care from Saudi nurses (Elmorshedy et al., 2020). Furthermore, Elmorshedy et al. (2020) indicated that $71.5 \%$ of the participants did not view nursing as a respected profession. The reasons are that their families would be embarrassed about what society would think and less than $50 \%$ of Saudi males prefer to marry a nurse.

Moreover, two items had low-level perceptions that nursing is a profession where anyone could be a nurse easily and that nursing is a women's profession. The results suggested that nursing students correctly recognized and perceived that nursing is not an easy degree and welcomes both genders, not only women. To become a nurse in Saudi Arabia is not an easy endeavor. Saudi nursing students take a total of five years to complete the nursing program, where they are trained in theoretical and clinical nursing competencies for four years before transitioning to newly graduated nurses through a one-year internship program (Aboshaiqah, Tumala et al., 2018). Although the percentage of men in nursing has persisted comparatively stagnant over time globally (Whitford et al., 2020), a study in Saudi Arabia reported that the number of Saudi men admitted to the nursing profession has increased significantly (Alboliteeh et al., 2017). Thus, the gender distribution is balanced, indicating a nondiscriminatory approach to the employment of both genders in the nursing workforce (Alboliteeh et al., 2017). In a study conducted in the United States of America (USA), the findings indicate that previous interventions aimed at creating a more welcoming environment for male nursing students at the research site have been moderately successful (Petges \& Sabio, 2020). Correspondingly, the lack of diversity in the nursing workforce including gender inequality directly impacts the capability to address healthcare discrepancies and provide high-quality and culturally competent nursing care (American Association of Colleges of Nursing, 2019). On the contrary, a previous study in Saudi Arabia revealed that the majority of the Saudi adults preferred to be cared for by female nurses, which stems from the perception that nursing is a women's profession. Moreover, Saudi cultural norms support that getting care by the opposite gender particularly for females is unacceptable (Elmorshedy et al., 2020). Similar findings were reported in another mixed-method study in Australia where of the 25 drawings of nursing students, 20 are female nurses, which is reflective that nursing is a women's profession (Browne et al., 2018). Meanwhile, the other two items had very low-level perceptions that the nursing profession is similar to that of the servant's job, where nurses waste a lot of time being busy doing nothing. The results of this study implied that nursing students viewed the role of nurses as professional caregivers and not just servant's jobs. That is, nurses are busy with their nursing tasks to help in patients' recovery from illness while maintaining the ethical standard of quality nursing care. The findings are consistent with those of a previous study, indicating that $76.4 \%$ of the 500 Saudi adult participants did not agree that the Saudi public sees the nursing profession as a servant's job (Elmorshedy et al., 2020).

Moreover, the overall level of agreement of the factors that cause drop-outs in the nursing program depicted a strong agreement from the nursing students with an overall mean score of 3.48 from 5 . The highest mean scores were reported with a strong agreement of the following factors that cause drop-outs, including increased study workload, illness or poor health, student dissatisfaction, low first- and second-year GPAs, difficulty in the English language, and clinical environment difficulties. The high levels of scores on the scale mean that nursing students may have experienced challenges while studying nursing caused by these factors. This finding was proven by the result that the nursing students' strong and positive agreement with their perceptions of nursing as a profession predicted their strong agreement that the above-identified factors cause drop-outs from the nursing program $(p=0.03)$. Similarly, a cross-sectional study in Saudi Arabia revealed that more than one-third of the nursing students' perceptions of the educational environment fell from having plenty of problems to very poor categories, which indicated areas of dissatisfaction from the nursing students (Al Nozha \& Fadel, 2017). This result was also observed in another study in Saudi Arabia, where nursing students are unsatisfied with their academic and social self-perception skills, which appeared to be a global phenomenon (Rawas \& Yasmeen, 2019). Another Saudi study reported that nursing students experienced the highest perceived stress from taking care of patients; too much stress can lead to low GPA, poor health, such as malnutrition, depression, and other mental health problems (Al-Gamal et al., 2018). In Taiwan, a previous study reported that nursing students' perception of the nursing professional image was significantly affected by learning 
environmental factors (Chen, 2016). Additionally, another study in Saudi Arabia reported that nursing students occasionally experience challenges in the clinical learning environment. These challenges were characterized by being unsupportive and insufficient to the development of competencies caused by the lack of opportunities to perform nursing procedures and having few nurses who cooperated and trusted to train them (Aboshaiqah, Roco et al., 2018). A similar finding was also reported regarding an increased study workload, where Saudi nursing students received too many requirements to study and comply with when having clinical training (Aboshaiqah, Roco et al., 2018). Moreover, the nursing students reported the English language as another factor that causes drop-outs in the current study. The nursing education is offered in English, but students' first language is Arabic. As most nursing faculties offer English courses during the nursing degree, the majority of nursing students managed well, whereas some of them struggled with the English language (Alharbi et al., 2019). Alharbi et al. (2019) added that, during their clinical education training, nursing students reported difficulty in communicating with hospital staff in English, who were mostly non-Arabic speakers. Furthermore, an integrative review confirmed this situation that although requiring students to learn and use English as a second language was not correlated with their intention to quit nursing school, this requirement had an impact on their GPA (Pitt et al., 2012). On the contrary, the clinical internship training of Saudi nursing students improved their compliance with standard precautions. This training helps decrease the difficulties they face in the clinical learning environment (Tumala, 2021), which is more important nowadays specifically during the COVID-19 pandemic. Additionally, the GPA of nursing students in another Saudi study was also linked with the challenges and in achieving good learning outcomes in the clinical environment. That is, higher GPAs are constantly challenged, which demanded hard work, focus, and countless trials for students to master the clinical nursing procedures to obtain a higher mark (Aboshaiqah, Roco et al., 2018). Hence, these findings call for more integrated and supportive clinical training and education regarding the factors that cause drop-outs in the pre-registration nursing program. This could help students to successfully transition to their nursing studies and graduate from the nursing program.

Finally, the overall agreement of nursing students with their intention to withdraw or quit nursing was low, as manifested by an overall mean score of 2.00 from 5 . The findings indicated that nursing students showed very strong disagreement about the thought of quitting and looking for another specialty the next year. Nonetheless, they reported a very strong agreement of choosing to study nursing if they could choose again. This result implied that nursing students did not intend to withdraw or quit from the nursing program. Similarly, among newly graduated nurses in the USA, the study showed that only $31 \%$ of the 154 study samples reported intention to quit their current work (Wu et al., 2012). The findings are contrary to a study in the Philippines. That is, firstyear nursing students were most fearful because of COVID-19, and their fear was correlated with their increased irritability, decreased sleep quality, and greater desire to quit nursing (De Los Santos et al., 2021). A previous study in Canada indicated that the perceptions of nursing students on nursing as a profession had been linked to their decisions to enter the nursing profession and to continue in or quit from the nursing program (Grainger \& Bolan, 2006), which is not evident in the current study.

\section{Limitations of the study}

The limitations of this study included using a convenience sample of participants, and students withdrawing from the program were not included in the study. The research design used which limited the causal relationship of the variables of the study was another limitation. The generalizability issue was also another limitation because of the limited sample of participants in a single university.

\section{Conclusions}

The study found that the perception of female Saudi nursing students about the nursing profession was positive. However, previous studies across the globe and in the country showed conflicting views. This finding should be addressed by investigating the perception of nursing students (males and females) and the public on a national scale to gain a wider and clear view of the perception of the nursing profession in the country. Students and public view of nursing can affect and influence high school students who are planning to enroll into the nursing program.

The perception of students on nursing as a profession predicted the factors that cause drop-outs: increased study workload, illness or poor health, student dissatisfaction, low first- and second-year GPAs, difficulty in the English language, and clinical environment difficulties. Thus, nursing faculties and academic administrators should address these factors. That is, they should provide the nursing students with the needed support and educational interventions by solving or eliminating those factors that are highly perceived to cause drop-outs from the nursing program. Furthermore, a constant and harmonious collaboration is needed between the academe and training institutions. This collaboration is fundamental for the effective and successful clinical training of nursing students, which could aid in reducing further their intention to leave the nursing program.

\section{References}

[1] Aboshaiqah, A. E., Tumala, R. B., Patalagsa, J. G., AlKhaibary, A. A., Fozan, H. A., \& Ben, J. P. (2018). Perceptions of confidence among Saudi nursing interns during internship program: a cross-sectional study. Annals of Saudi Medicine, 38(4), 288-298. https://doi.org/10.5144/0256-4947.2018.288

[2] Aboshaiqah, A., Roco, I., Pandaan, I., Baker, O., Tumala, R., \& Silang, J. (2018). Challenges in the clinical environment: The Saudi student nurses' experience. Education Research International, 2018, 1-9. https://doi.org/10.1155/2018/3652643

[3] Ahn, Y. H., \& Choi, J. (2019). Incivility experiences in clinical practicum education among nursing students. Nurse Education Today, 73, 48-53. https://doi.org/10.1016/j.nedt.2018.11.015

[4] Al Jarrah, I. A. T. (2013). Associate nursing students' perceptions toward nursing profession in Jordan. European Scientific Journal, 9(6), 1857-7881.

[5] Al Nozha, O. M., \& Fadel, H. T. (2017). Student perception of the educational environment in regular and bridging nursing programs in Saudi Arabia using the Dundee Ready Educational Environment Measure. Annals of Saudi Medicine,37(3), 225-231. https://doi.org/10.5144/0256-4947.2017.225

[6] Albaqawi, H. M., Alquwez, N., Balay-Odao, E., Bajet, J. B., Alabdulaziz, H., Alsolami, F., Tumala, R. B., 
Alsharari, A. F., Tork, H., Felemban, E. M., \& Cruz, J. P. (2020). Nursing Students' Perceptions, Knowledge, and Preventive Behaviors Toward COVID-19: A MultiUniversity Study. Frontiers in Public Health, 8, 573390. https://doi.org/10.3389/fpubh.2020.573390

[7] Alboliteeh, M., Magarey, J., \& Wiechula, R. (2017). The Profile of Saudi Nursing Workforce: A Cross-Sectional Study. Nursing Research and Practice, 2017, 1710686. https://doi.org/10.1155/2017/1710686

[8] Al-Gamal, E., Alhosain, A., \& Alsunaye, K. (2018). Stress and coping strategies among Saudi nursing students during clinical education. Perspectives in Psychiatric Care, 54(2), 198-205. https://doi.org/10.1111/ppc.12223

[9] Alharbi, M., McKenna, L., \& Whittall, D. (2019). Social barriers experienced by female Saudi nursing students while studying nursing: A phenomenological study. Nurse Education in Practice, 34, 123-129. https://doi.org/10.1016/j.nepr.2018.11.018

[10] Alkhamees, A. A., Alrashed, S. A., Alzunaydi, A. A., Almohimeed, A. S., \& Aljohani, M. S. (2020). The psychological impact of COVID-19 pandemic on the general population of Saudi Arabia. Comprehensive Psychiatry, 102,

https://doi.org/10.1016/j.comppsych.2020.152192

[11] Almutair, A., \& Redwan, F. (2016). Undergraduate Saudi nursing students' attitudes towards nursing profession. Journal of Nursing and Care, 5(1), 1000329. http://dx.doi.org/10.4172/2167-1168.1000329

[12] American Association of Colleges of Nursing (AACN). (2019). Enhancing diversity in the nursing workforce fact sheet. Retrieved from: https://www.aacnnursing.org/Portals/42/

News/Factsheets/Enhancing-Diversity-Factsheet2017.pdf.

[13] Andrew, S., Salamonson, Y., Weaver, R., Smith, A., O'Reilly, R., \& Taylor, C. (2008). Hate the course or hate to go: semester differences in first year nursing attrition. Nurse Education Today,28(7), 865-872. https://doi.org/10.1016/j.nedt.2007.12.007

[14] Brodie, D. A., Andrews, G. J., Andrews, J. P., Thomas, G. B., \& Rixon, L. (2004). Perceptions of nursing: confirmation, change and the student experience. International Journal of Nursing Studies, 41(7), 721-733.

[15] Browne, C., Wall, P., Batt, S., \& Bennett, R. (2018). Understanding perceptions of nursing professional identity in students entering an Australian undergraduate nursing degree. Nurse Education in Practice, 32, 90-96. https://doi.org/10.1016/j.nepr.2018.07.006

[16] Cammann,C., Fichman, M., Jenkins, D., \& Klesh, J. (1979). The Michigan Organizational Assessment Questionnaire. Unpublished manuscript, University of Michigan, Ann Arbor, MI.

[17] Cheng, C.-H. (2016). Perceptions of nursing image held by third and fourth year baccalaureate nursing students and related factors. The Journal of Nursing, 63(2), 91102.

[18] Clements, A. J., Kinman, G., Leggetter, S., Teoh, K., \& Guppy, A. (2016). Exploring commitment, professional identity, and support for student nurses. Nurse Education in Practice, 16(1), 20-26. https://doi.org/10.1016/j.nepr.2015.06.001
[19] De Los Santos, J. A. A., Labrague, L. J., \& Falguera, C. C. (2021). Fear of COVID-19, poor quality of sleep, irritability, and intention to quit school among nursing students: A cross-sectional study. Perspectives in Psychiatric Care, 1-8. https://doi.org/10.1111/ppc.12781

[20] Elmorshedy, H., Alamrani, A., Hassan, M., Fayed, A., \& Albrecht, S. (2020). Contemporary public image of the nursing profession in Saudi Arabia. BMC Nursing, 19. https://doi.org/10.1186/s12912-020-00442-w

[21] Grainger, P., \& Bolan, C. (2006). Perceptions of nursing as a career choice of students in the Baccalaureate nursing program. Nurse Education Today, 26(1), 38-44. https://doi.org/10.1016/j.nedt.2005.06.004

[22] Granum, V. (2004). Students' perceptions about nursing as a subject and as a function. The Journal of Nursing Education, $\quad 43, \quad 297-304$. https://doi.org/10.3928/01484834-20040701-08.

[23] Huang, B. H., \& Xiao, C. X. (2003) Investigation on the professional attitude of the nursing junior college students and undergraduate students. Journal of Nursing Science, 18 (9), 662-664.

[24] Jeffreys, M. R. (2015). Jeffreys's Nursing Universal Retention and Success model: overview and action ideas for optimizing outcomes A-Z.Nurse Education Today, 35(3), 425-431. https://doi.org/10.1016/j.nedt.2014.11.004

[25] Jinks, A. M., Richardson, K., Jones, C., \& Kirton, J. A. (2014). Issues concerning recruitment, retention and attrition of student nurses in the 1950/60s: A comparative study. Nurse Education in Practice, 14(6), 641-647. http://dx.doi.org/10.1016/j.nepr.20 14.07.002

[26] Johns Hopkins University and Medicine. (2021, August 8). Coronavirus COVID-19 Global Cases. Retrieved from the Coronavirus Resource Center at the website of Johns Hopkins University and Medicine: https://coronavirus.jhu.edu/map.html.

[27] Kim, J., Chae, D., \& Yoo, J. Y. (2021). Reasons Behind Generation Z Nursing Students' Intentions to Leave their Profession: A Cross-Sectional Study. Inquiry, 58, 46958021999928. https://doi.org/10.1177/0046958021999928

[28] Mansour, E. A., Gemeay, E. M., Behilak, S., \& Albarrak, M. (2016). Factors affecting Attrition Rate among Nursing Students College of Health Sciences, Taibah. International Journal of Nursing, 3(1), 65-72.

[29] Merkley, B. R.. (2016). Student nurse attrition: A half century of research. Journal of Nursing Education and Practice, 6(3), 71-75.

[30] National League for Nursing. (2012). Percentage of minority students enrolled in basic $R N$ programs by race ethnicity and program type, 2011. Retrieved from: http://staging.nln.org.

[31] Newton, S. E., \& Moore, G. C. (2009). Use of Aptitude to Understand Bachelor of Science in Nursing Student Attrition and Readiness for the National Council Licensure Examination-Registered Nurse. Journal of Professional Nursing, 25(5), 273-278.

[32] Petges, N., \& Sabio, C. (2020). Perceptions of male students in a baccalaureate nursing program: A qualitative study. Nurse Education in Practice, 48, 102872. https://doi.org/10.1016/j.nepr.2020.102872.

[33] Pitt, V., Powis, D., Levett-Jones, T., Hunter, S., 2012. Factors influencing nursing students' academic and 
clinical performance and attrition: an integrative literature review. Nurse Education Today, 32(8), 903913.

[34] Rawas, H., \& Yasmeen, N. (2019). Perception of nursing students about their educational environment in College of Nursing at King Saud Bin Abdulaziz University for Health Sciences, Saudi Arabia. Medical Teacher, 41(11), 1307-1314.

https://doi.org/10.1080/0142159X.2019.1638502

[35] Saied, H., Al Beshi, H., Al Nafaie, J., \& Al Anazi, E. (2016). Saudi Community Perception of Nursing as a Profession. IOSR Journal of Nursing and Health Science, 5(2), 95-99.
[36] Tumala, R. B. (2021). Predictors of nursing interns' standard precautions compliance during internship training in four teaching hospitals in Saudi Arabia. International Journal of Nursing Practice, 27(3), e12897. https://doi.org/10.1111/ijn.12897

[37] Whitford, H., Marland, G., Carson, M., Bain, H., Eccles, J., \& Taylor, J., 2020. An exploration of the influences on under-representation of male pre-registration nursing students. Nurse Education Today, 84, 1-5. https://doi.org/10.1016/j. nedt.2019.104234.

[38] Wu, T. Y., Fox, D. P., Stokes, C., \& Adam, C. (2012). Work-related stress and intention to quit in newly graduated nurses. Nurse Education Today, 32(6), 669 674. https://doi.org/10.1016/j.nedt.2011.09.002 